\title{
Analyzing the Topographical Evolution Characteristics of a Bay over the Last 50 Years
}

\author{
Han $\mathrm{Si}^{*}$ \\ The Second Surveying and Mapping Institute of Zhejiang Province, Hangzhou, China
}

Received: 24 January 2018

Accepted: 20 March 2018

\begin{abstract}
Based on coastline, water depth, and remote sensing image data of Sanmen Bay over the past 50 years, this research analyzed quantitatively coastline temporal-spatial evolution characteristics and underwater topography evolution characteristics. The results showed that the total coastline length of Sanmen Bay first decreased and then increased during the last 50 years. The most obvious change of total coastline length occurred from the 1960s to the 1990s. However, in this period, the natural coastline had a higher percentage and a slower change rate. After the 1990s, with artificial interference gradually increasing, the coastline experienced a change process of the curving coastline becoming a straight coastline and moving outward continually. Although the length variation is small, the spatial form of the bay has changed significantly. After 2007 the artificial coastline accounted for more than $70 \%$. From the 1960 s to 2015 , coastline and 0 meter isobath showed the trend of moving outward. The bay area decreased and most channels deposited. In general, the underwater topography in 2015 was more complex than that in the 1960s. Human activity had a critical role of affecting branch development in the Sanmen Bay area.
\end{abstract}

Keywords: coastline, Sanmen Bay, evolution characteristics, erosion and deposition, underwater topography

\section{Introduction}

A bay area is a border region of land and sea As one of the most frequent material and energy exchange areas, bays are easily affected by eustasy, diastrophism, and changes in land-sea distribution [1-3]. Coastal zones located in the concentration areas of population and economic activities have fragile

*e-mail: sihan.101@163.com geological and ecological environment, and increasing contradictions of resources and environment problems [4-7]. As development and utilization continue, human activities such as land reclamation, coastal engineering construction, and aquaculture make great contributions to gulf economic development, while at the same time bringing many negative effects [8-9]. Reclaiming the land from the sea causes a decrease in bay area and the tidal prism, and reduces tidal current velocity, which leads to gulf siltation and affects water exchange [10-13]. 
Sanmen Bay is a typical semi-closed strong tide bay with multiple channels and has a certain representativeness in coastal bays of Zhejiang Province [14-16]. There are multiple islands in the bay and long coastline twists and turns. A multistage branching stream embedded inland and alternated arrangement with a large lingulate tidal flat constitute a unique landscape of the Zhejiang-Fujian coast. This area holds significant economic status in Zhejiang, which has been driving a continuous reclamation project for a long time [17-19]. Under the marine resources development boom, the influence of human activities on Sanmen bay has far more than the role of natural influence. In the face of great environmental pressure, human concerns began to pay more attention to ecological and environmental benefits instead of only the pursuit of economic interests [20-24].

This research aimed to disclose landform evolution characteristics in Sanmen Bay within the last 50 years. First we analyzed quantitatively the coastline temporalspatial evolution process from the 1960s to 2015, and calculated the changing rate of coastline length in different periods. Secondly, in order to explore underwater topography evolution characteristis we analyzed isobath distribution from the 1960 s to 2015 , calculated volume and area of subwater topography erosion and deposition, and researched erosion and deposition distribution characteristics of the main branching streams.

\section{Material and Methods}

\section{Study Area}

Sanmen Bay is located in the central coastline of Zhejiang Province across Ninghai, Xiangshan, and Sanmen counties. It is NW-SE oriented, with the northern neighbor being Xiangshan Harbor and the southern one Taizhou Bay. Its latitude and longitude range from $28^{\circ} 57^{\prime} \mathrm{N}$ to $29^{\circ} 22^{\prime} \mathrm{N}$, and from $121^{\circ} 25^{\prime} \mathrm{E}$ to $121^{\circ} 58^{\prime} \mathrm{E}$, respectively.

The study area has a subtropical monsoon climate with four distinct seasons, moderate weather, and abundant rainfall. The annual average precipitation is $1375.3 \mathrm{~mm}$, with more than $80 \%$ falling in the period from March to September. The annual average wind speed ranges from 1.9 to $5.6 \mathrm{~m} / \mathrm{s}$, and the annual average number of fog days ranges from 13 to 54.6.

Sanmen Bay has bedrock coast and muddy coast, as well as artificial coastline. Numerous islands in the bay weaken the dynamic effect, along with a certain fine particulate matter source, and the muddy coast is so well developed. This bay has abundant tideland resources, with branching streams embedded in lingulate tidal flat. Tidal prism is considerable, with a mean tidal range of $4 \mathrm{~m}$. Tidal range increases gradually from the bay mouth to the northwest inside the bay. The tidal current is of an irregular semi-diurnal one. The flood tidal duration

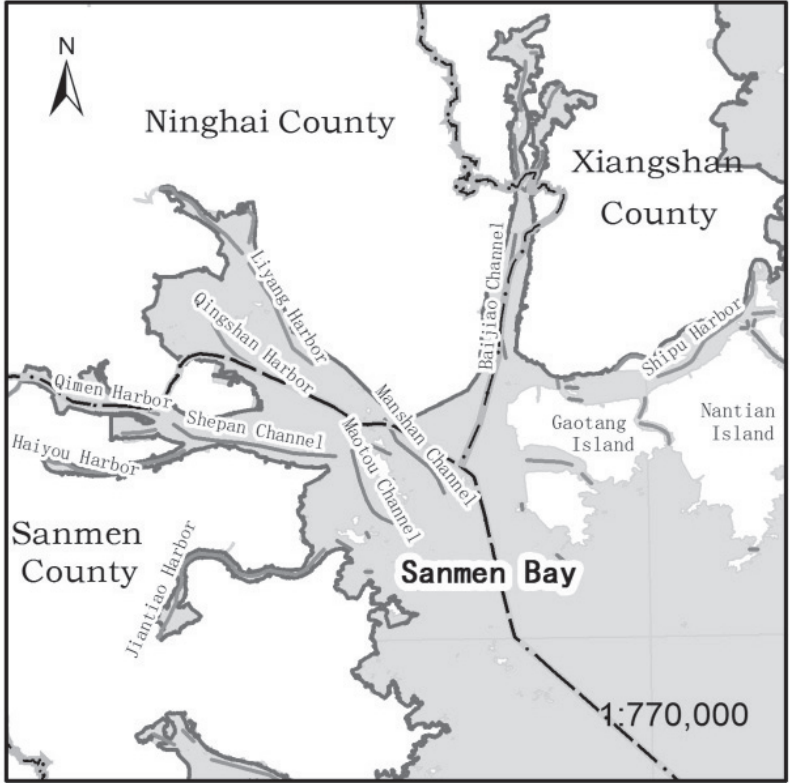

Fig. 1. Location of Sanmen Bay.

is larger than the ebb tide, while the flood current velocity is slower than the ebb current in the whole tidal process. And the seasonal variation is not obvious. The maximum flood is $155 \mathrm{~cm} / \mathrm{s}$, ebb is $179 \mathrm{~cm} / \mathrm{s}$.

\section{Data Source}

For researching landform evolution characteristics of Sanmen Bay with a longtime scale, this study involved different plotting scales and data sources, including mainly coastline, water depth, remote sensing image, and auxiliary data.

\section{Coastline Extraction}

First, coordinate systems of five phases of coastline data must be unified because of different coordinate reference systems and the projection mode of the spatial data from different sources [25-27]. The coastline data adopted CGCS2000 coordinate systems and Gauss-Kruger projection of central longitude 120 degrees.

Coastline in the 1960s was extracted from a Landsat TM remote sensing image map of 1964. First, the remote sensing image was enhanced to improve contrast. In the meantime, the coastline was modified with reference to the sea and aviation maps. The coastline was classified into two types: artificial and natural coastlines. Artificial structures were mainly constructed by cement and stone, and had relatively high spectral reflectance. External edges of the dyke were taken as artificial coastline. The natural coastline was the line of water and land boundary [28-30].

Coastline in 1990s was extracted from the sea map of Sanmen Bay, which was measured in 1998. The coastline was also classified into artificial 
Table 1. Basic data classificat.

\begin{tabular}{|c|c|c|c|c|}
\hline & Name & Format & Year & Coordinate system \\
\hline \multirow{4}{*}{ Coastline data } & $\begin{array}{l}\text { Continental coastline of Zhejiang } \\
\text { province }\end{array}$ & Shape & 2011,2015 & CGCS2000 \\
\hline & $\begin{array}{l}\text { Continental coastline of Zhejiang } \\
\text { province }\end{array}$ & Shape & 2007 & Xi'an 1980 \\
\hline & Continental coastline of Sanmen Bay & JPG & 1998 & Beijing 1954 \\
\hline & $\begin{array}{c}\text { Remote sensing image of Sanmen } \\
\text { Bay }\end{array}$ & Landsat TM & 1964 & UTM-WGS84 \\
\hline \multirow{2}{*}{ Water depth data } & Sea map of Sanmen Bay & JPG & 1960s & Beijing 1954 \\
\hline & Water depth data of Sanmen Bay & GDB & 2015 & CGCS2000 \\
\hline $\begin{array}{l}\text { Remote sensing } \\
\text { image data }\end{array}$ & $\begin{array}{c}\text { Remote sensing image of Sanmen } \\
\text { Bay }\end{array}$ & $\begin{array}{c}\text { Landsat5 TM, } \\
\text { Landsat8 OLI_TRIS }\end{array}$ & $\begin{array}{l}\text { 1990s and each phase } \\
\text { of the data in recent } \\
\text { years }\end{array}$ & UTM-WGS84 \\
\hline Auxiliary data & $\begin{array}{c}\text { 1:10000 Fundamental Geographic } \\
\text { Information Database of Zhejiang } \\
\text { Province }\end{array}$ & GDB & 2015 & CGCS2000 \\
\hline
\end{tabular}

coastline and natural coastline. The data was unified to CGCS2000 coordinate systems after vectorization.

\section{Coastline Variation Rate Calculation}

Based on multiple periods of historical coastline data, coastline variation rate was calculated by adopting the endpoint rate method to analyze coastline change characteristics [31-32]. This method divides the moving distance between two positions by time lag, and the formula is as follows:

$$
E P R=\frac{D_{2}-D_{1}}{T_{2}-T_{1}}
$$

...where $\mathrm{D}_{1}$ and $\mathrm{D}_{2}$ are the position data of time $\mathrm{T}_{1}$ and $\mathrm{T}_{2}$, respectively.

\section{Water Depth Data Processing}

Change of erosion and deposition was affected by various factors such as water and sediment transport, suspended load, and bed load movement [33-38]. A large volume of sediment deposition will lead to a barred dam, which is disadvantageous to water exchange [39-41]. It is important in its actual significance and practical application value to research underwater topography evolution characteristics [42-44]. Water depth data contained two periods of data: in the 1960s and 2015. The data of the 1960s, collected from a sea map of Sanmen Bay, was first vectorized and its coordinate system unified to CGCS2000. The data was analyzed by ARCGIS 10.3.

(1) Create TIN: Creating a TIN model by first using the 3D Analyst extended module. After model generation we can add, remove, or modify the TIN node and intersecting line directly to make the model more reasonable with real-time feedback of the model surface.

(2) TIN to Raster: After all the TIN models generation, converting TIN to Raster files for calculating volume and area of erosion and deposition.

(3) Erosion and deposition variation: Digital erosion and deposition variation maps could be obtained by making overlay analysis of two periods of raster files with "Minus" in "Spatial Analyst Tools."

(4) Volume of erosion and deposition: Erosion volume and deposition volume are calculated by "Surface volume" in "3D Analyst Tools."

(5) Area of erosion and deposition: Raster data is reclassified to count the grid number of erosion and deposition. Multiply the grid number by the area of each raster to get the total area of erosion and deposition.

\section{Results and Discussion}

\section{Coastline Temporal-Spatial Evolution Process}

\section{From the 1960s to 1990 s}

Total coastline length of Sanmen Bay presented a decreasing tendency from the 1960s to the 1990s. In the $1960 \mathrm{~s}$, the total coastline length was 476.61 $\mathrm{km}$. Where artificial coastline length was $186.74 \mathrm{~km}$, accounting for $39.18 \%$, and was mainly artificial revetment and ebb dyke between farmland, pond, and tidal flat. Natural coastline length was $289.87 \mathrm{~km}$ and was mainly bedrock distributed at Xieqian Harbor and south of Jiantiao Harbor.

In the $1990 \mathrm{~s}$ the total coastline length was $389.72 \mathrm{~km}$, which decreased by $18.23 \%$ compared with that in the 1960s. Human activities, including 

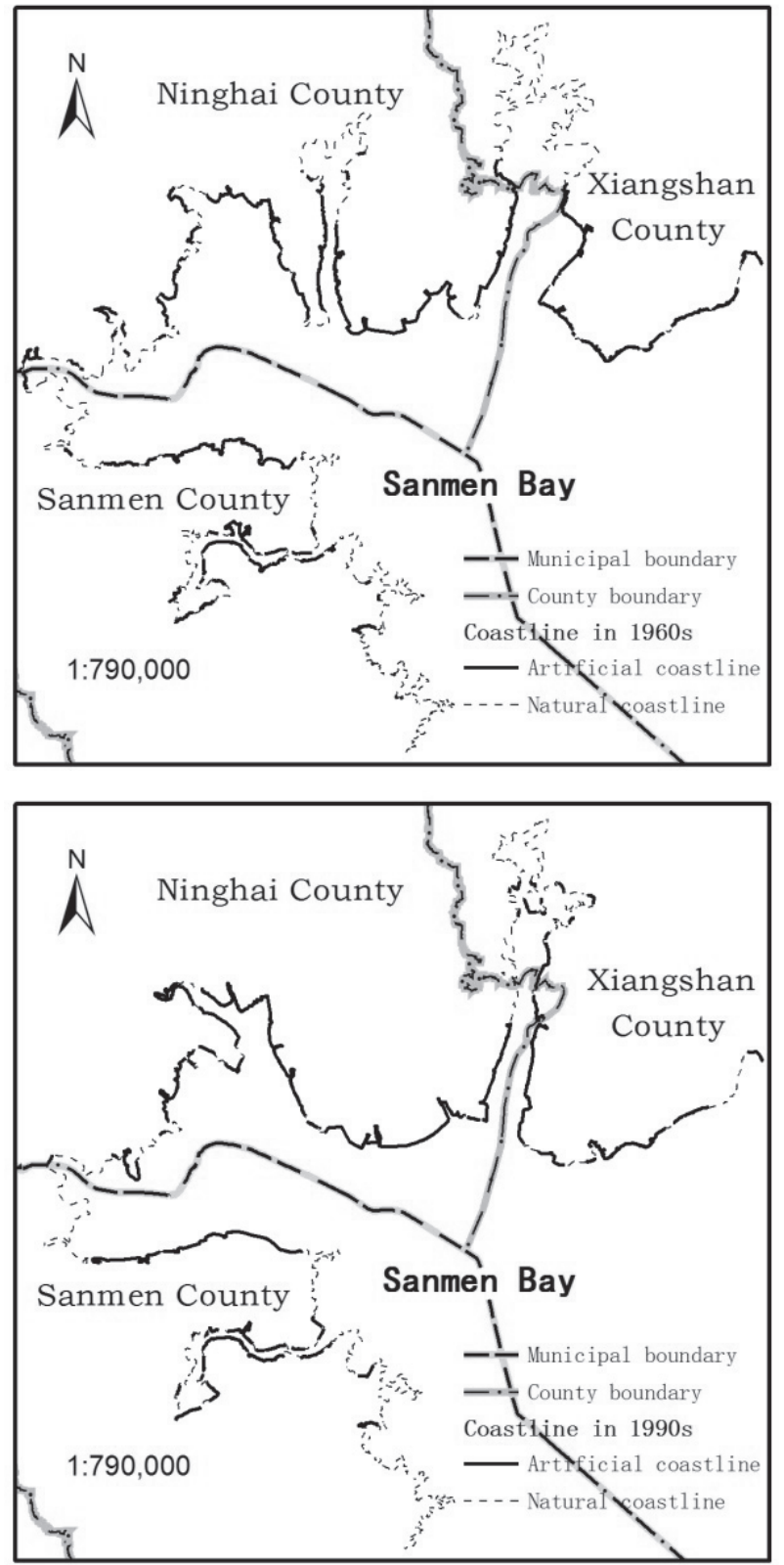

Fig. 2. Coastline distribution maps of Sanmen Bay in the 1960s and 1990s.

construction of embankments and culture ponds and the reclamation project were the dominant factors to influence coastline change. South of Xiangshan County, due to the construction of culture ponds and ebb dykes, islands were turned into inland, leading to the mainland coastline length decreasing and the coastal zone area increasing. In southern Ninghai County, Huchen Harbor was turned into the inland Huchen Reservoir after the 1990s due to water conservancy construction, and the mainland coastline length decreased significantly. Artificial coastline and natural coastline in the $1990 \mathrm{~s}$ were $174.31 \mathrm{~km}$ and $215.41 \mathrm{~km}$, respectively, and both decreased compared with length in the 1960s.

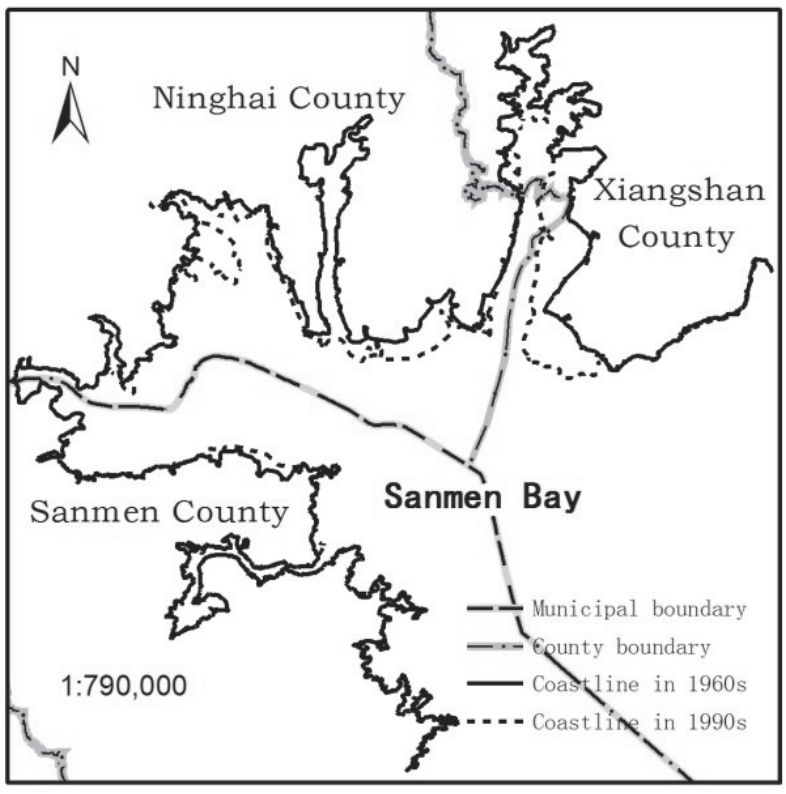

Fig. 3 Coastline comparison map of the 1960s and 1990s.

From the 1990s to 2007

In 2007 total coastline length was $373.13 \mathrm{~km}$, which had decreased by $4.26 \%$ compared with that in the 1990 s and did not appear to be much different. The coastline showed the trend of moving toward the outside region of the bay and changed significantly in the south of Sanmen County and in the north of Ninghai County. As shown in Fig. 6, in the 1990s two islands did not belong to the mainland. The northern island was Shepan, which was the largest island in Sanmen County. In 1992, Shepan village was established and was connected

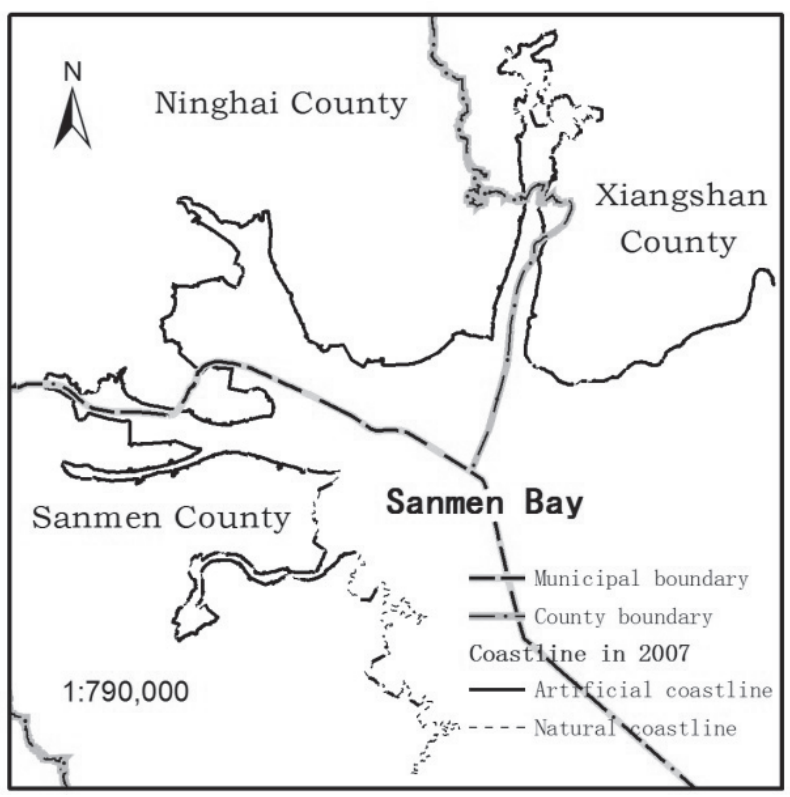

Fig. 4. Coastline distribution map of Sanmen Bay in 2007. 


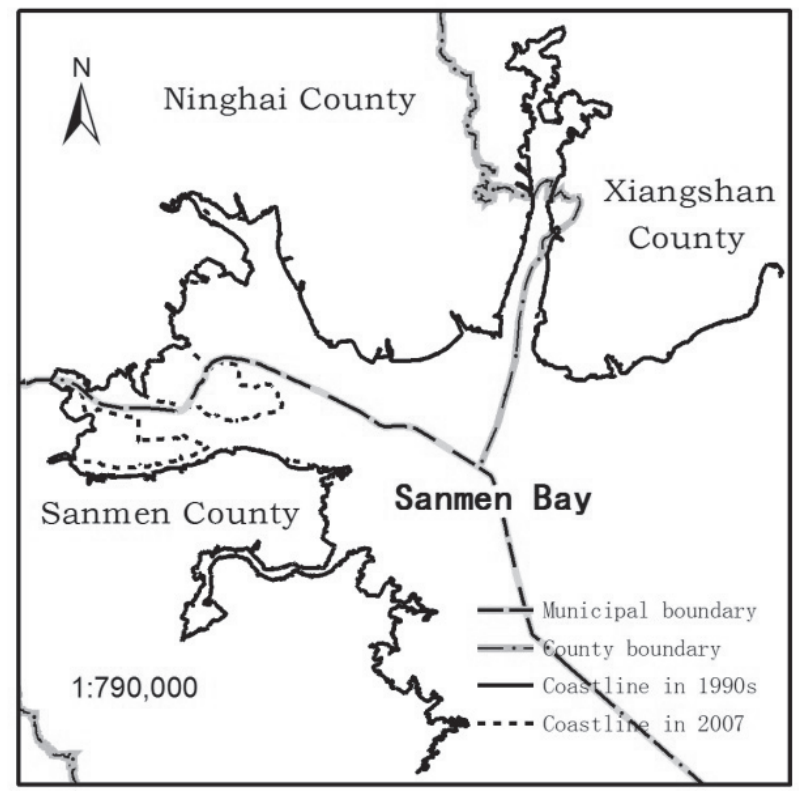

Fig. 5. Coastline comparison map of the 1990s and 2007.
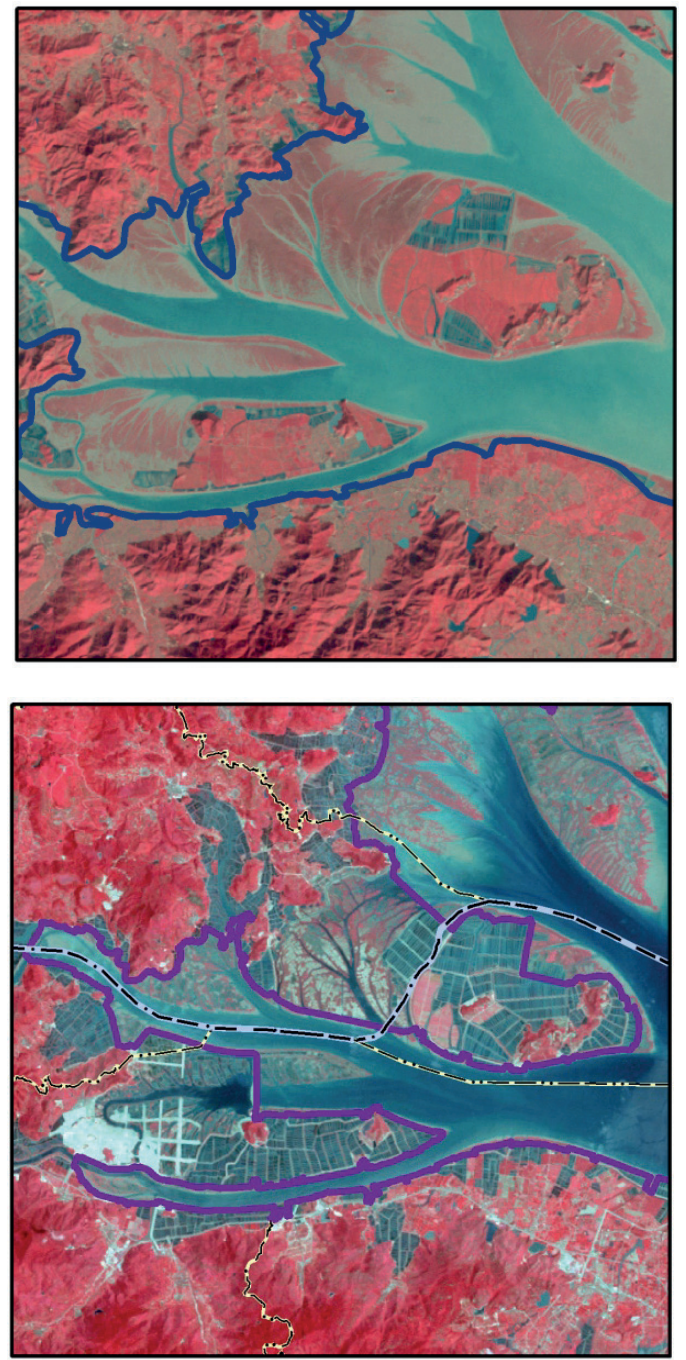

Fig. 6. Remote sensing image comparison map of the 1990s and 2007.

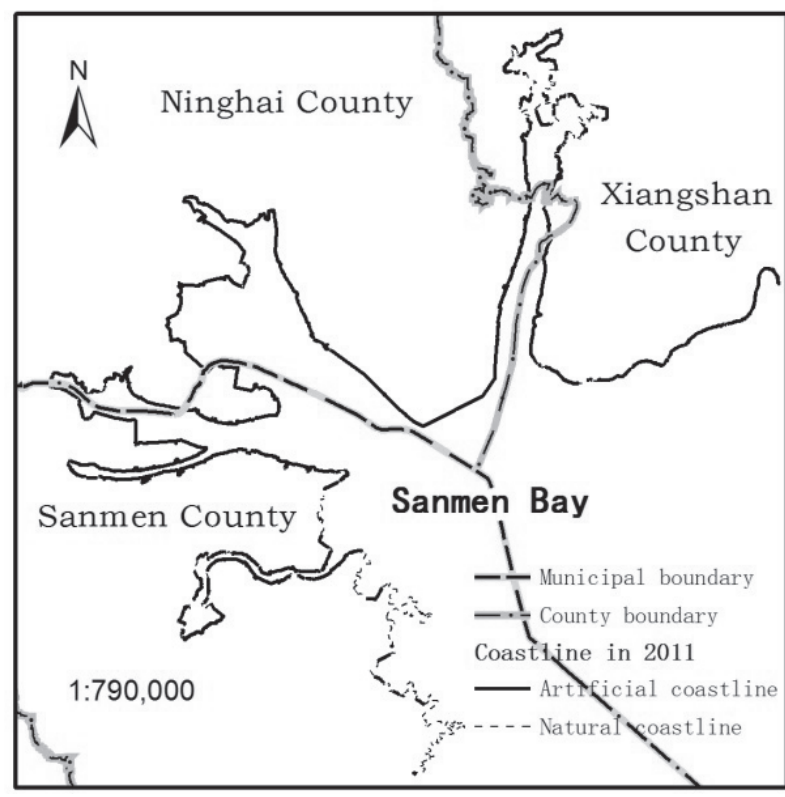

Fig. 7. Coastline distribution map of Sanmen Bay in 2011.

with the mainland gradually to be a peninsula due to reclamation projects. The southern island was Huagu, which was the second largest island in Sanmen County. In 1992 this island belonged to the town of Liuao and was connected with the mainland gradually due to mudflat aquaculture development. However, multiple culture pond construction inside gulfs from the 1990s to 2007 led to the curving natural or artificial coastline becoming straight artificial coastline, which contributed to the total coastline length decreasing.

The artificial coastline in 2007 was $262.61 \mathrm{~km}$, which had increased significantly compared to the 1990s, and accounted for $70.38 \%$ of total coastline length.

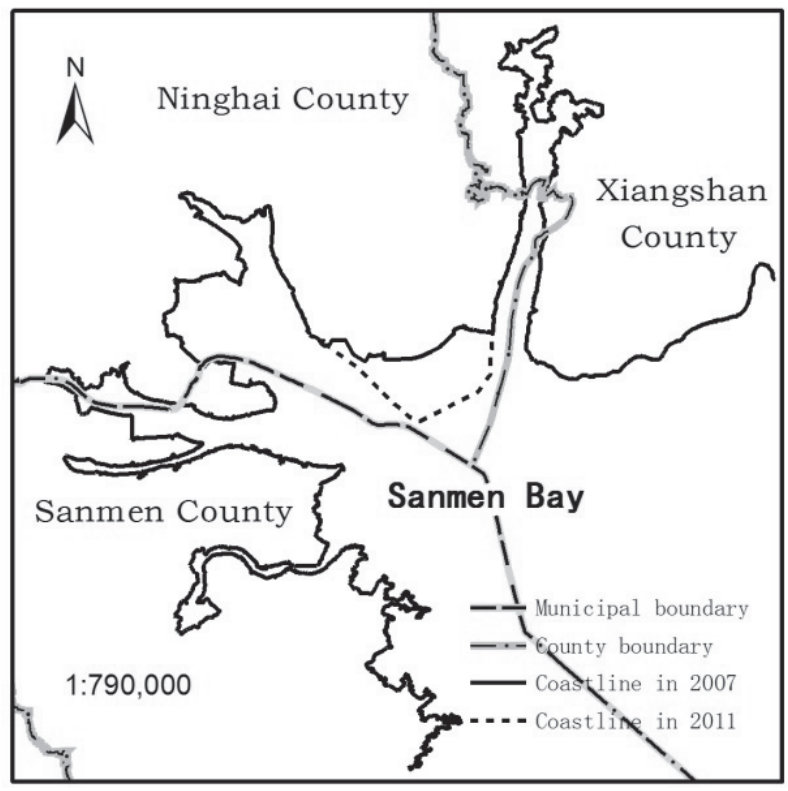

Fig. 8. Coastline comparison map of 2007 and 2011. 

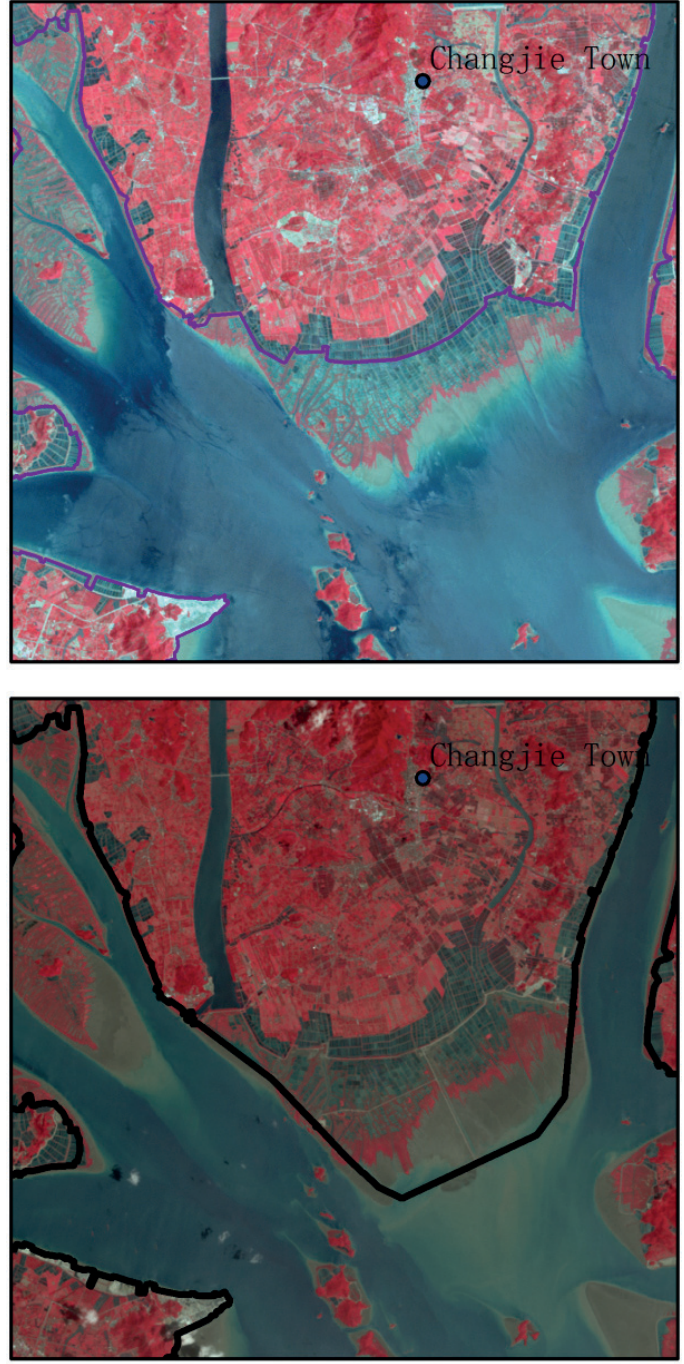

Fig. 9. Remote sensing image comparison map of 2007 and 2011.

The natural coastline was just $110.52 \mathrm{~km}$, and mainly existed in Xieqian Harbor and south of Jiantiao Harbor.

\section{From 2007 to 2011}

The total coastline length of Sanmen Bay in 2011 was $379.27 \mathrm{~km}$, and it did not appear to be much different compared with that in 2007. The coastline change mainly occurred in the south of Ninhai County. This area was Xiayangtu in 2007, the largest tidal flat resource in Ninghai County, and was classified as part of Changjie town in 2011. The Xiayangtu reclamation project was a priority project of Zhejiang Province. The preliminary work had been launched officially at the beginning of 2007 and the project was fully completed in January 2013. As shown in Fig. 9, in 2011 Xiayangtu was classified as part of the mainland, but the level of land exploitation and utilization was still low.

Artificial coastline in 2011 was $271.82 \mathrm{~km}$, increased by $3.51 \%$ compared with that in 2007 . While the natural coastline was $107.45 \mathrm{~km}$ and decreased by $2.78 \%$. In the meantime, the proportion of artificial

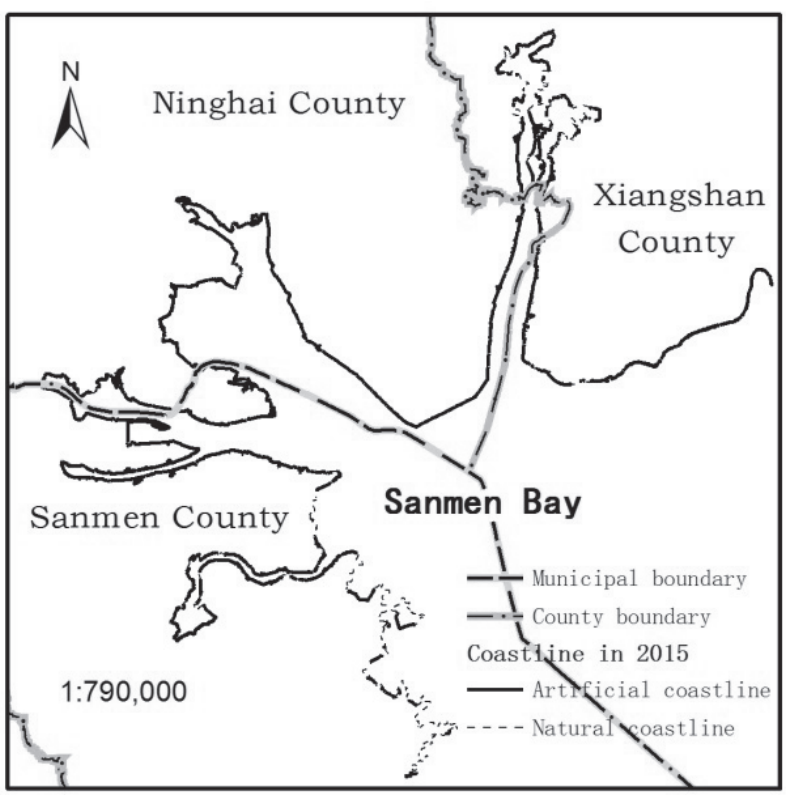

Fig. 10. Coastline distribution map of Sanmen Bay in 2015.

coastline continued to grow and increased to $71.67 \%$ in 2011 .

\section{From 2011 to 2015}

The total coastline length of Sanmen Bay in 2015 was $423.11 \mathrm{~km}$, which increased by $11.56 \%$ compared with that in 2011. The proportion of artificial coastline continued to grow and increased to $77.41 \%$ in 2015 . From 2011 to 2015, the coastal zone area just increased by $10.57 \mathrm{~km}^{2}$, and did not appear to be much different. The reclamation projects mainly occurred in Hairun

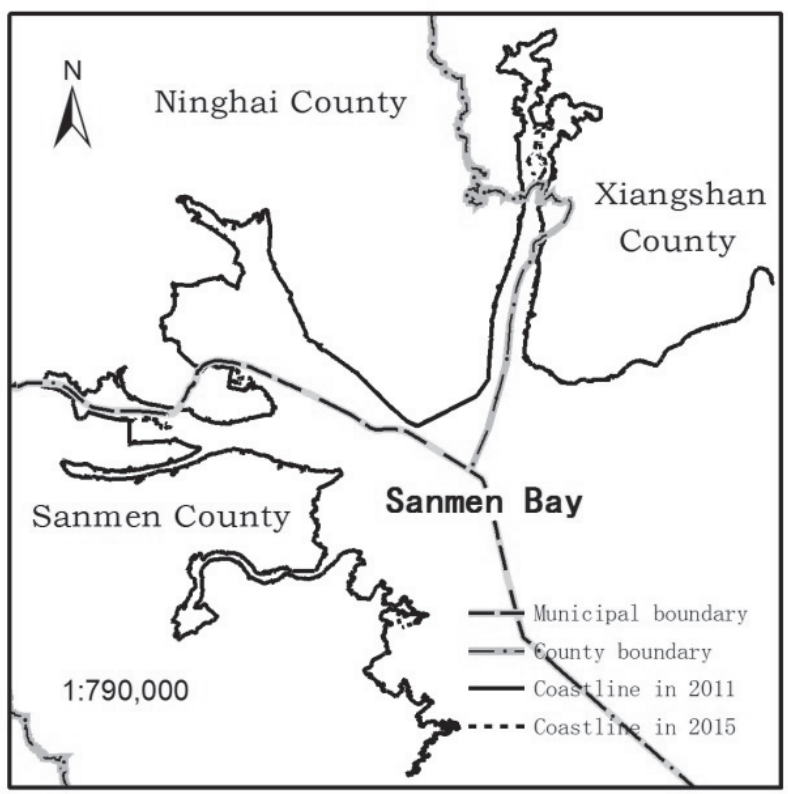

Fig. 11. Coastline comparison map of 2011 and 2015. 


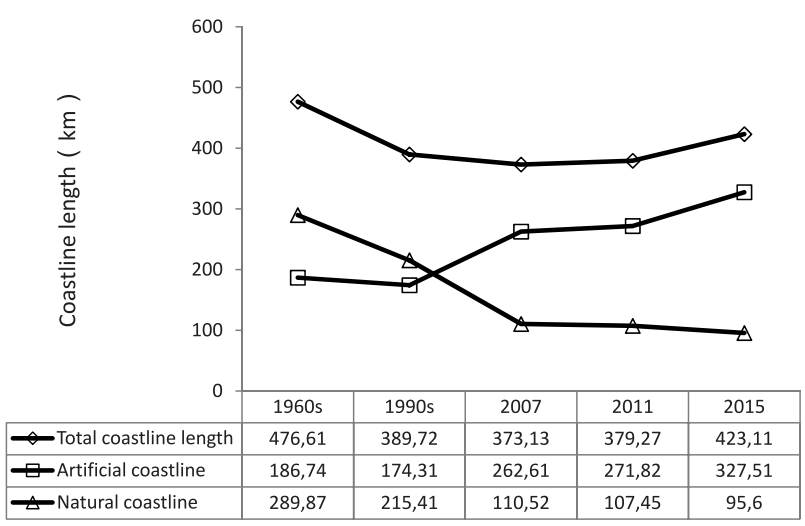

Fig. 12. Coastline length inter-annual variation.

subdistrict and Shepan village of Sanmen County, and the town of Xinqiao in Xianshan County.

\section{Change Rate Analysis of Coastline Length}

The total coastline length of Sanmen Bay first decreased and then increased during the last 50 years. The most obvious change of total coastline length occurred from the $1960 \mathrm{~s}$ to the $1990 \mathrm{~s}$. Man-made embankments, culture ponds, and water conservancy projects significantly influenced coastline change. However, from the $1960 \mathrm{~s}$ to the $1990 \mathrm{~s}$ the natural coastline had the higher percentage and the slower change rate. The total coastline length decreased by $2.56 \mathrm{~km}$ a year.

After the 1990s, with artificial interference gradually increasing, the coastline experienced a change process of the curving coastline, becoming a straight coastline and moving outward continually. The total coastline length also first decreased and then increased. Although the variation is small, spatial form of the bay changed significantly. Shepan and Huagu islands connected with the mainland as part of the Xiayangtu reclamation project, and coastline changes in Xieqian Harbor were due to manual work on coastline form in the short term. The total coastline length change had the fastest rate from 2011 to 2015, increasing $10.96 \mathrm{~km}$ a year. After 2007, artificial coastline accounted for more than $70 \%$. The natural coastline was just $95.6 \mathrm{~km}$ in 2015 . The influence of manual work on coastline was more and more pronounced.

Table 2. Coastline change rate analysis $(\mathrm{km} / \mathrm{a})$

\begin{tabular}{|c|c|c|c|}
\hline & $\begin{array}{c}\text { Total } \\
\text { coastline length }\end{array}$ & $\begin{array}{c}\text { Artificial } \\
\text { coastline }\end{array}$ & $\begin{array}{c}\text { Natural } \\
\text { coastline }\end{array}$ \\
\hline $1960 \mathrm{~s}-1990 \mathrm{~s}$ & -2.56 & -0.37 & -2.19 \\
\hline $1990 \mathrm{~s}-2007$ & -1.84 & 9.81 & -11.65 \\
\hline $2007-2011$ & 1.54 & 2.30 & -0.77 \\
\hline $2011-2015$ & 10.96 & 13.92 & -2.96 \\
\hline $1960 \mathrm{~s}-2015$ & -1.05 & 2.76 & -3.81 \\
\hline
\end{tabular}

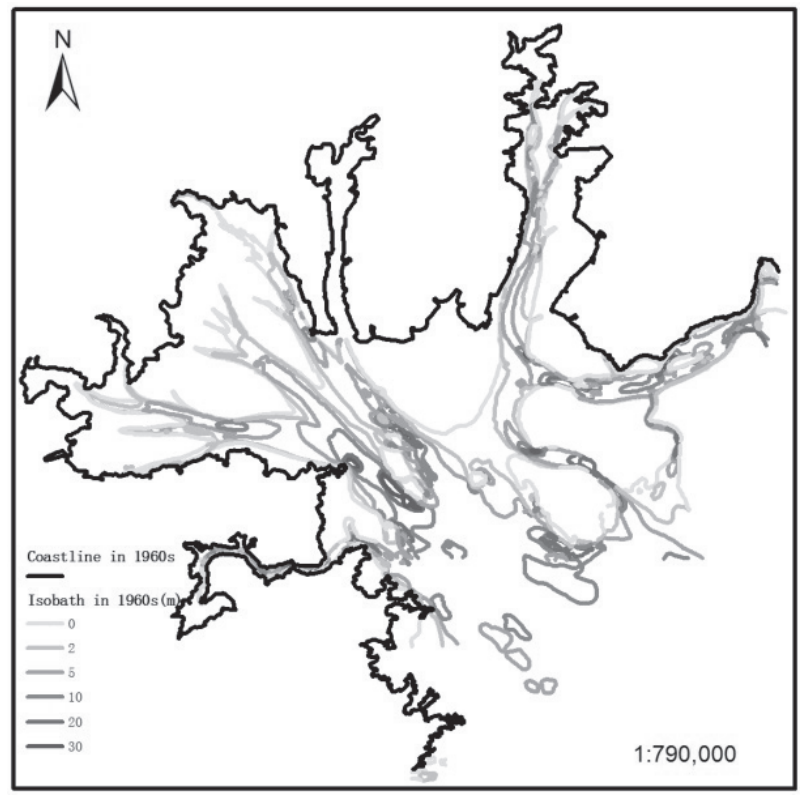

Fig. 13 Coastline and isobath distribution in 1960s.

\section{Underwater Topography Evolution Characteristics}

This research analyzed tidal flat and underwater topography evolution characteristics of Sanmen Bay based on water depth data in the 1960s and 2015, which corresponded to coastline data in the 1960s and 2015, respectively. Since Huchen Harbor was turned into inland Huchen Reservoir after the 1980s, this area was not studied when analyzing subwater topography erosion and deposition characteristics.

Coastline and isobath distribution in the 1960s are shown in Fig. 13. Sanmen Bay had few large lingulate

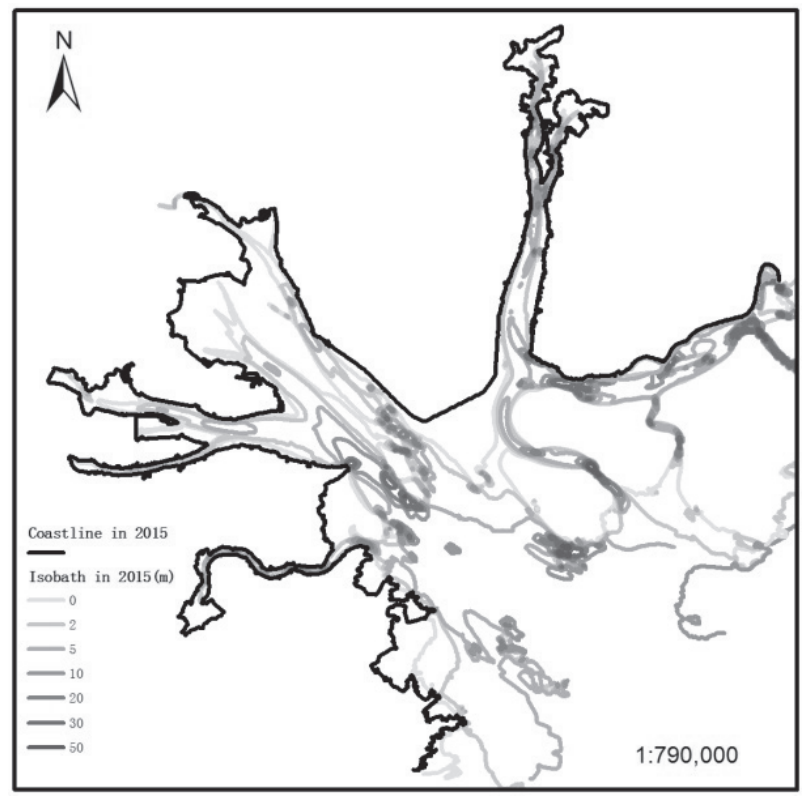

Fig. 14 Coastline and isobath distribution in 2015. 


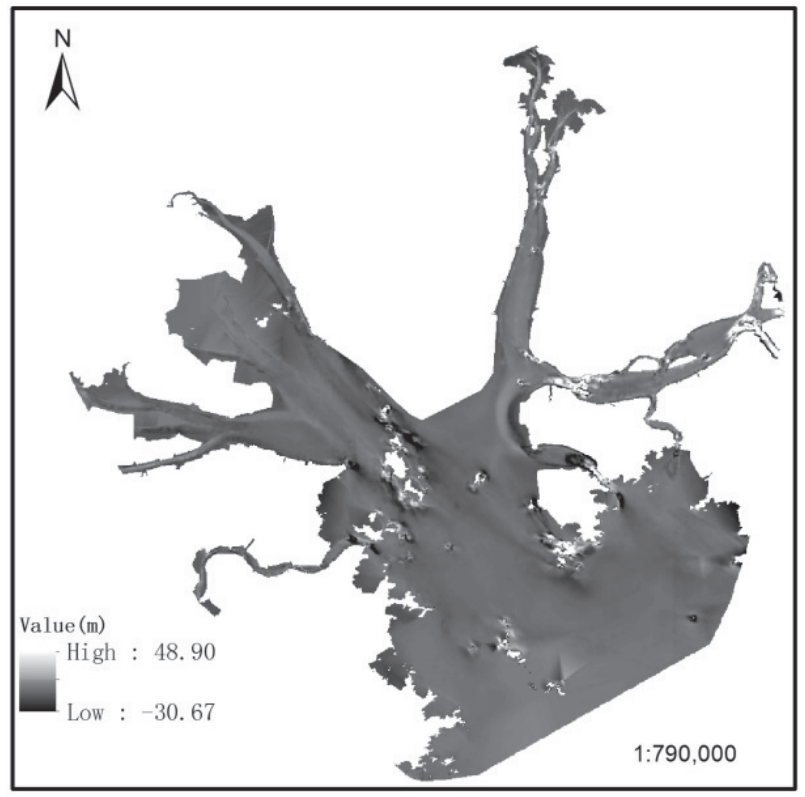

Fig. 15. Variation of underwater topography erosion and deposition in Sanmen Bay.

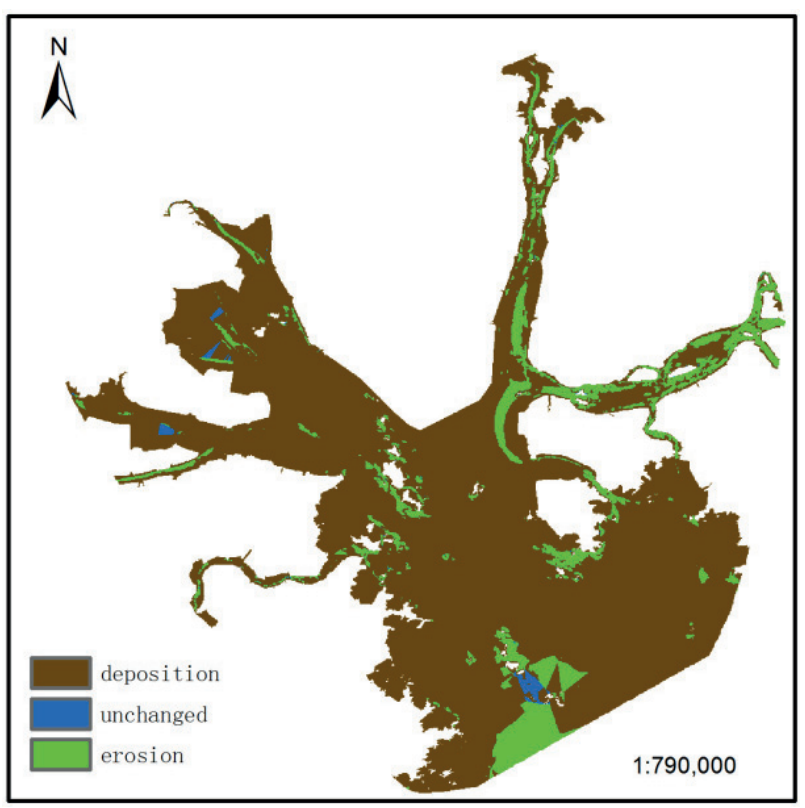

Fig. 16. Variation distribution of underwater topography erosion and deposition.

tidal flats, such as Baijiao Channel and Qingshan, Liyang, Qimen, and Haiyou harbors. A multistage branching stream embedded inland and alternated arrangement with lingulate tidal flats. The tide flats were wide and the isobaths were sparse in Qingshan, Liyang, Qimen, and Haiyou harbors, where there was relatively simple underwater topography. The isobaths of Jiantiao Harbor and Baijiao Channel were dense and deep into the mainland. The deepest isobaths of these two places were $20 \mathrm{~m}$ and $30 \mathrm{~m}$, respectively, and the underwater topography was steeper. Shepan, Manshan, and Maotou channels were connected with Qingshan, Liyang, Qimen, and Haiyou harbors, and had complex underwater topography. There were many islands in this area. The isobaths gradually increased in depth outward around the island, were dense and distributed in a disorderly manner, and formed the multiple channel structure. Shipu Harbor also had complex underwater topography and a narrow tidal flat. The isobaths were distributed densely and the underwater topography was steep. There were many islands in the harbor. The deepest isobath was $30 \mathrm{~m}$.

Form 1960 s to 2015 , coastline and 0 meter isobath showed the trend of moving outward. The bay area decreased and most channels deposited. The deepest isobath was $50 \mathrm{~m}$ in 2015, which exists in the south of Huaao island and Gaotang island, and the east of Shipu Harbor. In general, the underwater topography in 2015 was more complex than that in the 1960s.

Variation of underwater topography erosion and deposition in Sanmen Bay is presented in Fig. 15. The deepest erosion depth from the 1960s to 2015 was $48.9 \mathrm{~m}$, in eastern Shipu Harbor. The deepest deposition depth was $30.67 \mathrm{~m}$, in the south of Gaotang Island. We used the surface volume tool to calculate erosion and deposition volumes from the 1960 s to 2015 , which were $1.95 * 10^{8} \mathrm{~m}^{3}$ and $1.32 * 10^{9} \mathrm{~m}^{3}$, respectively. Deposition volume was 6.8 times the erosion volume. As seen in Fig. 16, erosion areas were mainly in Baijiao Channel, Haiyou Harbor, Shipu Harbor, and the middle of Maotou Channel and Manshan Channel. In Haiyou Harbor and Baijiao Channel, the middle eroded and the two sides deposited, and the underwater topography was steeper. Shipu Harbor and the middle of Maotou Channel and Manshan Channel were multiple channel structures, and the erosion and deposition distribution was not obvious.

Erosion and deposition conditions of six main branches are shown in Table 3. From the 1960s to 2015, the deposition area of each branch was bigger than the erosion area, and deposition volumes were larger than erosion volumes besides Shipu Harbor.

Shipu had the deepest erosion depth, and the average erosion depth was $5.18 \mathrm{~m}$. In addition, the region of Shepan and Manshan channels also had greater erosion and deposition depths, and unstable underwater topography. Shipu Harbor, Shepan Channel, and Manshan Channel were the route connected with open seas, influenced significantly by tide and topography. Qingshan, Liyang, Qimen, and Haiyou harbors had relatively shallow erosion and deposition depths, and a wider range of deposition. Human activity such as reclamation and dams contributed to the coastline and tidal flat moving outward gradually, promoting the tidal flat deposition, and had taken a critical role of affecting branch development in Sanmen Bay. 
Table 3. Erosion and deposition conditions of six main branches in Sanmen Bay.

\begin{tabular}{|c|c|c|c|c|c|c|}
\hline & $\begin{array}{c}\text { Baijiao } \\
\text { Channel }\end{array}$ & $\begin{array}{c}\text { Shipu } \\
\text { Harbor }\end{array}$ & $\begin{array}{c}\text { Jiantiao } \\
\text { Harbor }\end{array}$ & $\begin{array}{c}\text { Qingshan } \\
\text { Harbor-Liyang } \\
\text { Harbor }\end{array}$ & $\begin{array}{c}\text { Qimen } \\
\text { Harbor-Haiyou } \\
\text { Harbor }\end{array}$ & $\begin{array}{c}\text { Shepan } \\
\text { Channel-Manshan } \\
\text { Channel }\end{array}$ \\
\hline Erosion volume $\left(10^{4} \mathrm{~m}^{2}\right)$ & 1556.67 & 7935.01 & 111.17 & 117.03 & 160.48 & 1567.38 \\
\hline Deposition volume $\left(10^{4} \mathrm{~m}^{2}\right)$ & 8061.01 & 2587.69 & 2414.28 & 15021.23 & 4986.08 & 24322.21 \\
\hline Net erosion volume $\left(10^{4} \mathrm{~m}^{2}\right)$ & 0 & 5347.32 & 0 & 0 & 0 & 0 \\
\hline Net deposition volume $\left(10^{4} \mathrm{~m}^{2}\right)$ & 6504.34 & 0 & 2303.11 & 14904.19 & 4825.61 & 22754.84 \\
\hline Erosion area $\left(10^{4} \mathrm{~m}^{2}\right)$ & 948.40 & 1531.76 & 105.74 & 275.64 & 151.78 & 517.42 \\
\hline Deposition area $\left(10^{4} \mathrm{~m}^{2}\right)$ & 4056.17 & 1845.12 & 989.39 & 7649.88 & 2073.53 & 9053.92 \\
\hline Average erosion depth $(\mathrm{m})$ & 1.64 & 5.18 & 1.05 & 0.42 & 1.06 & 3.03 \\
\hline Average deposition depth $(\mathrm{m})$ & 1.99 & 1.40 & 2.44 & 1.96 & 2.40 & 2.69 \\
\hline
\end{tabular}

\section{Conclusions}

The total coastline length of Sanmen Bay first decreased and then increased over the last 50 years. The most obvious change of total coastline length occurred from the 1960 s to the 90 s. However, in this period, the natural coastline had a higher percentage and slower change rate. The total coastline length decreased $2.56 \mathrm{~km}$ a year. After the ' $90 \mathrm{~s}$, with artificial interference gradually increasing, the coast line experienced a change process of curving coastline becoming straight coastline and then moving outward continually. The total coastline length first decreased and then increased. Although the variation is small, the spatial form of the bay has changed significantly. Shepan and Huagu islands connected with the mainland, Xiayangtu reclamation project, and coastline change in Xieqian Harbor were the impact of manual work on coastline form in the short term. After 2007, artificial coastline accounted for more than $70 \%$. The natural coastline was just $95.6 \mathrm{~km}$ in 2015. The influence of manual work on the coastline was more and more pronounced.

From the 1960 s to 2015 , coastline and 0 meter isobath showed the trend of moving outward. The bay area decreased and most channels deposited. In general, the underwater topography in 2015 was more complex than that in the 1960 s. Form the 1960 s to 2015 the deposition area of each branch was bigger than the erosion area, and deposition volumes were larger than erosion volumes besides Shipu Harbor. Human activity had a critical role of affecting branch development in the Sanmen Bay area.

\section{Acknowledgements}

This research was supported by "Researching the impact of Human activity on topography evolution characteristics of Sanmen Bay" (No. ZCKJ2016007) and "Research on typical cultivated land change scenario simulation in rural area of Zhejiang Province" (No. ZCKJ2017010).

\section{Conflict of Interest}

The authors declare no conflict of interest.

\section{References}

1. GIORGIO M., GIORGIO A., ENRICA M., ALLAN T.W., MIGUEL S., VINCENZO L. Decadal evolution of coastline armouring along the Mediterranean Andalusia littoral (South of Spain). Ocean \& Coastal Management, 124, 84, 2016.

2. HÉCTOR J.P.G., OMAR D.R., JAIME H.B., MARÍA Á.L.G., VÍCTOR M.P.G., FERNANDO H.B., SAMUEL C.L. Determining Water Salinity in a Shallow Aquifer and Its Vulnerability to Coastline Erosion. Polish journal of environmental studies, 26 (5), 2001, 2017.

3. OLUSEGUN A.D., LI G.X., QIAO L.L., MA Y.Y., DING D., XU J.S., LI P., YANG J.C. Response of waves and coastline evolution to climate variability off the Niger Delta coast during the past 110 years. Journal of Marine Systems, 160, 64, 2016.

4. CAWTHRA H., BATEMAN M., CARR A., COMPTON J., HOLMES P. Understanding Late Quaternary changes at the land-ocean interface: The evolution of the Wilderness coastline, South Africa. Quaternary International, 404 (Part B), 196, 2016.

5. ZHANG W., WU J.Z., LI W.R., ZHU L.H., HU R.J., JIANG S.H., SUN Y.G., WANG H.J. Beach morphology and coastline evolution in the southern Bohai Strait. Journal of Ocean University of China, 14 (5), 803, 2015.

6. PENG J., MA S.S., CHEN H.Q., LI Z.W. Temporal and spatial evolution of coastline and subaqueous geomorphology in muddy coast of the Yellow River Delta. Journal of Geographical Sciences, 23 (3), 490, 2013.

7. PATRICK W.L., A. B.M. Beach and sea-cliff dynamics as a driver of long-term rocky coastline evolution and stability. Geology, 39 (12), 1147, 2011.

8. PRANZINI E., FARRELL E.J. Shoreline Evolution and Protection Strategies Along the Tuscany Coastline, Italy. Journal of Coastal Research, 22, 842, 2006. 
9. MORHANGE C., GOIRAN J. -P., BOURCIER M., CARBONEL P., LE CAMPION J., ROUCHY J. -M., YON M. Recent Holocene paleo-environmental evolution and coastline changes of Kition, Larnaca, Cyprus, Mediterranean Sea. Marine Geology, 170 (1-2), 205, 2000.

10. ZHANG X.F., YUAN Y., QI M.J. Impact of terrain complexity on the accuracy of calculations of river channel storage volume derived from measurements of underwater topography. Arabian Journal of Geosciences, 8 (11), 9149, 2015.

11. YAN X.L., HU Y.M., CHANG Y., LI Y.H., LIU M., ZHONG J.Q., ZHANG D.H., WU W. Effects of Land Reclamation on Distribution of Soil Properties and Heavy Metal Concentrations, and the Associated Environmental Pollution Assessment. Polish journal of environmental studies, 26 (4), 1809, 2017.

12. CHERDVONG S. Erosion protection options of a muddy coastline in Thailand: Stakeholders' shared responsibilities. Ocean \& Coastal Management, 83, 81, 2013.

13. SANDRINE A., JEAN-PIERRE T. Coastal Erosion, Processes and Rates: An Historical Study of the Gironde Coastline, Southwestern France. Journal of Coastal Research, 16 (3), 756, 2000.

14. LI T.J., GUO Y.M., JIA Y.R., ZHANG X.J., ZHANG Y.R., XUE B. Environment Quality Assessment and Analysis in Sanmen Bay sea area. Transactions of Oceanology and Limnology, 3, 123, 2011 [In Chinese with English abstract].

15. CHEN X.Y., ZHANG J., MA Y., CUI T.W. Monitoring and analysis of coastline changes of the Sanmen Bay with remote sensing during the past 40 years. Marine Sciences, 39 (2), 43, 2015 [In Chinese with English abstract].

16. CHEN Z.H., MAO Z.H., CHEN J.Y. Coastline Change Monitoring Using 4 Periods Remote Sensing Data in Zhejiang Province from 1986 to 2009. Remote sensing technology and application, 26 (1), 68, 2011 [In Chinese with English abstract].

17. PENG K.R. Response of the hydrodynamic environment to Sanmen Bay reclamation. Zhejiang University, 2013 [In Chinese with English abstract].

18. XIA X.M. Stability of tidal inlet in the Sanmen Bay. Zhejiang University, 2011 [In Chinese with English abstract]

19. YANG H.Y., XUE B., JIN L.X., ZHOU S.S., LIU W.P. Polychlorinated biphenyls in surface sediments of Yueqing Bay, Xiangshan Bay, and Sanmen Bay in East China Sea. Chemosphere, 83 (2), 137, 2011.

20. WU J.Q., YU H.M., GE C.J., XIAO M., TANG W.H. Study on Land Use/Land Cover and Driving Mechanism in Bay Area Based on RS and GIS. Journal of Hainan Normal University(Natural Science), 25 (2), 206, 2012.

21. EKERCIN S. Coastline change assessment at the aegean sea coasts in turkey using multitemporal landsat imagery. Journal of Coastal Research, 23 (3), 691, 2007.

22. HAN X.Q. Study on the evolution of the coastline in the last hundred years in Hebei. Hebei Normal University, 2008 [In Chinese with English abstract].

23. ZHAO H.X., WANG S.F. Evaluation of Space-Time Pattern on Haze Polluttion and Associated Health Losses in the Yangtze River Delta of China. Polish journal of environmental studies, 26 (4), 1885, 2017.

24. CHEN H.X., HUA F., LIU N., SUN X.P. Study on Variability of Coastline and Water Depth of Jiaozhou Bay in Recent Years. Advances in Marine Science, 27 (2), 149, 2009 [In Chinese with English abstract].
25. FU Y., GUO Q.Z., WU X.X., FANG H., PAN Y.Y. Analysis and Prediction of Changes in Coastline Morphology in the Bohai Sea, China, Using Remote Sensing. Sustainability, 9 (6), 900, 2017.

26. WANG D.P., BING Z.W., LI Y.B., CHEN X., YU L. Coastline Variation Monitoring and Analysis of Northern Liaodong Bay Based on Multi-source Remote Sensing Data. Geology and Resources, 24 (4), 365, 2015.

27. XU N., GAO Z.Q., NING J.C. Analysis of the characteristics and causes of coastline variation in the Bohai Rim (1980-2010). Environmental Earth Sciences, 75 (8), 1, 2016

28. MOHAMMAD M., GHOLAMREZA A. Coastline extraction from SAR images using spatial fuzzy clustering and the active contour method. International Journal of Remote Sensing, 38 (2), 355, 2017.

29. ZENG Q.L. Mainland Shoreline Change Analysis of Shandong Province on Remote Sensing Since 1986. Shandong University of Science and Technology, 2012 [In Chinese with English abstract].

30. GONG L.X., JIN B.F., LI J.Y. The changing of typical bay coastline in Yantai in recent 20 years. Marine Sciences, 32 (11), 64, 2008 [In Chinese with English abstract].

31. LIU L. Spatial Resources Utilization Tempo-spatial evolution of Jiaozhou Bay Coastal Zone. The First Institute Of Oceanography, Soa, 2008.

32. ZHANG Y., LU X.Q., SHAO X.L., CHEN C., LI X.J., ZHAO F., LI G., EIJIJ M. Temporal variation of sedimentation rates and potential factors influencing those rates over the last 100 years in Bohai Bay, China. Science of The Total Environment, 572, 68, 2016.

33. GONG M.J. Research on the erosion and deposition of underwater topography in the radiation sandbar. Nanjing Normal University, 2009.

34. HELENE B., JON F. Understanding coastal change using shoreline trend analysis supported by cluster-based segmentation. Geomorphology, 282, 131, 2017.

35. GEORGE P.P., DIONISSIOS P.K., HYWEL M.G., PARASKEVI P.D. Remote sensing and GIS analysis for mapping spatio-temporal changes of erosion and deposition of two Mediterranean river deltas: The case of the Axios and Aliakmonas rivers, Greece. International Journal of Applied Earth Observation and Geoinformation, 35 (Part B), 217, 2015.

36. NABILA H., SAFA F., MONCEF G. Beach and nearshore morphodynamic changes of the Tabarka coast, Northwest of Tunisia. Environmental Earth Sciences, 66 (4), 1059, 2012.

37. MUSTAFA D., FATIH U., M. SAMI A. Prediction of cross-shore sandbar volumes using neural network approach. Journal of Marine Science and Technology, 20 (1), 171, 2015.

38. MUSTAFA D., M. SAMI A. Investigation of bar parameters occurred by cross-shore sediment transport. International Journal of Naval Architecture and Ocean Engineering, 5( 2), 277, 2013.

39. HE L. Effects of Human Activities in the Wei River Basin on the Lower Yellow River, China. Polish journal of environmental studies. 26 (6), 2555, 2017.

40. PENG J., CHEN S.L., LI G.Q., LIU F., CHEN G.Q. Evolution of Coastline and Subaqueous Geomorphology off the Survived River Mouth in the Yellow River Delta. Acta Geographica Sinica, 67 (3), 368, 2012 [In Chinese with English abstract].

41. CUI B.L., LI X.Y. Coastline change of the Yellow River estuary and its response to the sediment 
and runoff (1976-2005). Geomorphology, 127(1-2), 32, 2011.

42. WANG Y.H., PETER V.R., WU H.L., WU J.X., SHEN H.T. Long-term morphodynamic evolution and the equilibrium mechanism of a flood channel in the Yangtze Estuary (China). Geomorphology, 99 (1-4), 130, 2008.

43. HAN J.Q., SUN Z.H., HUANG Y., LI Y.T. Features and causes of sediment deposition and erosion in Jingjiang reach after impoundment of the Three Gorges Project. Journal of Hydraulic Engineering, 45 (3), 277, 2014 [In Chinese with English abstract].

44. XEIDAKIS G.S., DELIMANI P., SKIAS S. Erosion problems in Alexandroupolis coastline, North-Eastern Greece. Environmental Geology, 53 (4), 835, 2008. 
